\title{
In vitro propagation, callus culture and phytochemical profiling of Manjishtha-A invaluable medicinal species of Leh-Ladakh
}

\author{
Ankita Sharma, Shardulya Shukla, Abul Quasim, Manoj Kumar Patel, Raj Kumar, Om Prakash Chaurasia and \\ Shweta Saxena \\ Medicinal and Aromatic Plant Division, Defence Institute of High Altitude Research (DRDO), Chandigarh-160022, India
}

\section{Article Info}

Article history

Received 5 May 2021

Revised 21 June 2021

Accepted 22 June 2021

Published online 30 June 2021

\section{Keywords}

Ladakh

Manjishtha

Micropropagation

GC-MS

\begin{abstract}
Ladakh, a high altitudinal Indian state situated in trans-Himalayan region, is well known for its extreme ecosphere, rugged topography and scarce vegetation with peculiar ability to biosynthesize a number of phytochemicals. Rubia cordifolia L. is one of such herb known for its phytochemical enriched roots. Since the outbreak of COVID-19, a great emphasize has been given towards the exploration of health beneficial plants. Keeping this in view, in present study, an in vitro regeneration protocol has been developed using nodal and leaf explant followed by a comparative determination of phytochemical profile of in vitro grown leaves (RUML) and roots RUMR. MS basal medium supplemented with $1.0 \mu \mathrm{M}$, each of BAP and $\mathrm{KN}$ was found optimum for production of maximum number of shoots $(42.33 \pm 1.43)$ from nodal explant and $8.33 \pm 0.88$ in leaf explant. Further, $99.67 \pm 0.33 \%$ rooting was achieved in $0.1 \mathrm{mg} / \mathrm{l} \mathrm{NAA}$ supplemented MS media. GC-MS profiling of methanolic extract of RUML and RUMR revealed a total of 31 phytocompounds in both extracts with 8 compounds, commonly present in both extract describing the medical potential of both leaves as well as roots.
\end{abstract}

\section{Introduction}

Phytochemicals, God's boons of healing power in plants describes the scientific base of application of plants as eternal source of food and drugs to mankind. These are the non-nutritive constituents of plant-based diet with disease-preventing or curative capabilities to humans (Surh, 2003). Biosynthesis of these metabolites are carried out mostly through secondary metabolism, resulting in production of chemically and taxonomically varied compounds with diverse range of biological activities, viz., pharmaceutical applications in human therapy, veterinary, agriculture, scientific research and in numeral other areas (Morton, 1981; Ogunmefun, 2018). The plant kingdom is a treasure trove of many potential drugs. In recent decade, usage of plants with medicinal properties are achieving more popularity among public due to their considerable less side effects in comparison to synthetic drugs fascinating people around world to look for the natural resources of new drugs (Johnson and William, 2002). It has been documented that $80 \%$ of human public around the globe has a strong belief in traditional medicine, especially in drugs from plant origin for their primary healthcare (Tsay and Agrawal, 2005; Bin-Nyeem and Mannan, 2018). A number of organic compounds belonging to different classes of phytoactive constituents, viz., tannins, alkaloids,

Corresponding author: Dr. Shweta Saxena

Scientist F, Medicinal and Aromatic Plant Division, Defence Institute of High Altitude Research (DRDO), Chandigarh-160022, India E-mail: shweta.dipas@gmail.com

Tel.: +91-9810192610

Copyright (c) 2021 Ukaaz Publications. All rights reserved.

Email: ukaaz@yahoo.com; Website: www.ukaazpublications.com carbohydrates, phenols, terpenoids, anthocyanins, steroids and flavonoids are suggested to be responsible for these therapeutical and physiological actions on the human body (Badyal et al., 2003; Bin-Nyeem and Mannan, 2018). Undoubtly, plant kingdom is a rich reservoir of numeral medicinal plants species however, their medicinal attributes should be unraveled for better understanding of their safety and efficiency (Arunkumar and Muthuselvam, 2009; Yadav and Agarwala, 2011).

Rubia cordifolia L., also known as Indian Madder or Manjhistha, is a perennial, flowering plant species belonging to Rubiaceae family. Plants of this species are found to have more or less cylindrical four angled stem with sharp recurved prickles on the ridges and white flowers arranged in cyme inflorescence (Warrier et al., 2001, Devi and Siril, 2014). Since ancient times, roots of $R$. cordifolia have been found to be used as ingredient in different herbal formulations like in Chadanasava for treatment of urinogenetal disorders, Jatyaadi Ghrita for chronic and septic ulcers; Phala Sarpi Ghrita and Phal Kalyaan Ghrita for amenorrhoea, Manjisthadi Taila (oil) for headaches, ring worm and numeral other fungal infections (Shekokar et al., 2013; Venugopal, 2002). Decoction of manjistha cooked with ghee and Moringa oleifera is useful for bleeding piles, etc. Numerous biologically active compounds belonging to different classes, viz., anthraquinones and their glycosides, naphthoquinones and glycosides, terpenes, bicyclic hexapeptides, iridoids, carboxylic acids (malic, citric, quinic, rosmarinic acids) and saccharides (xylose, ribose, fructose, glucose, sucrose, primverose) have been reported in various parts of $R$. cordifolia (Itokawa et al., 1990; Son et al., 2008; Devi and Siril, 2014). 
Ladakh, an Indian union territory state, is situated in high altitude region of trans-Himalayas at an altitude ranging from $8000 \mathrm{ft}$ to 24000 $\mathrm{ft}$ above mean sea level (Kala and Manjrekar, 1999). This region is well known for its rugged ecosystem, scree slopes, low vegetation and for extreme climatic features such as high UV radiation (120000 lux), reduced water precipitation $(20-30 \mathrm{~mm}$ annual rainfall), subzero temperatures, etc., (Kumar et al., 2013). Barren mountains of Ladakh Himalayas, which otherwise seem parched and devoid of vegetation at first site, are wealthy in medicinally important herbs and approximately 1100 different species have been reported in this region, forming the basis of local Amchi medicinal system (Navchoo and Buth, 1989). $R$. cordifolia is one of such medicinal plant species, found to grow near water source in summer season. It is a well known fact that plant do a lot of changes in their cellular and genetic constitution in order to adapt to existing natural environmental conditions. Biosynthesis and accumulation of phytochemicals is one of such approach which depends on prevailing various external environmental factors, viz., temperature, humidity, light intensity, water stress and $\mathrm{CO}_{2}$ concentration (Gharibi et al., 2016). However, limited growing season make this plant unavailable throughout the year for extraction of phytochemicals. Plant cell culture is a promising technique for extraction of phytochemicals under controlled conditions of environment irrespective of external conditions. Further, selection of source of explants is necessary for efficient production of phytochemicals as biosynthesis and accumulation of phytochemicals under influence of ectopic environment in tissue/organ specific. Therefore, present study has been carried out to establish an in vitro propagation protocol for $R$. cordifolia growing in Leh using two explant types, viz., leaf and nodal explants followed by GC-MS analysis of methanolic extract of in vitro grown leaves (RUML) and roots (RUMR) for determining phytochemical profile of both extracts.

\section{Materials and Methods}

\subsection{Chemicals}

All components of MS medium and growth regulators were purchased from Sigma Aldrich Pvt. Ltd. Water used for media preparation and various analyses were used from Merck Millipore Academic instrument. Analytical grade methanol was purchased from Merck and Qualigens Fisher Scientific.

\subsection{Plant material and source of explants}

Healthy, disease-free plantlets and certified seeds of $R$. cordifolia were collected from herbal garden maintained at Defence Institute of High Altitude research (DRDO), Leh of India in the month of June (Figure 1)

\subsection{Explants preparation}

Two types of explants, viz., leaf and nodal segments were used for establishment of in vitro culture of $R$. cordifolia. Nodal explant was prepared by cutting the stem at internodal portion, whereas leaves were used directly by cutting from their petioles. Both of the explants were soaked in 5\% Tween-20 solution and bevistein for half an hour followed by thorough washing under running tap water for $2 \mathrm{~h} 3 \mathrm{~min}$. Further, three step surface sterilization of explants was carried out by using ethanol $(70 \%(\mathrm{v} / \mathrm{v}))$ for 120 secs, $\mathrm{HgCl}_{2}(0.04 \%(\mathrm{w} / \mathrm{v}))$ for 60 secs accompanied by thorough washing with autoclaved distilled water (4-5 times) to remove the remaining traces of sterilizing agents.
2.4 Establishment of aseptic culture from nodal and leaf explants

Both surface sterilized explants were cut carefully and inoculated on MS basal medium having sucrose (3.00\%; w/v), agar $(0.78 \%$; w/ v) and different combinations of PGRs, i.e., BAP KN and NAA for efficient shoot induction (Tables 1 to 3 ). $\mathrm{pH}$ of the medium was adjusted to 5.8 before addition of agar. Following which, the culture medium was autoclaved for $15 \mathrm{~min}$ at $120^{\circ} \mathrm{C}$. Inoculations were carried out in aseptic condition and kept at a temperature of $22 \pm$ $2{ }^{\circ} \mathrm{C}$ and $70-80 \%$ relative humidity conditions. Photoperiod cycle of $16 / 8 \mathrm{~h}$ was maintained by using light illumination of $40 \mu \mathrm{mol} / \mathrm{m}^{2}$ $\mathrm{s}$ with help of cool white fluorescent lamps. Readings were noted after 45 days of inoculation.

\subsection{Rooting of in vitro regenerated shoots}

Regenerated shoots from both the explants were excised carefully, separated and transferred to root induction medium containing three different concentrations, viz., $0.5 \mathrm{mg} / \mathrm{l}, 0.1 \mathrm{mg} / \mathrm{l}$ and $0.2 \mathrm{mg} / \mathrm{l}$ of each of NAA and IBA (auxins) respectively, to get complete plantlets. Inoculated shoots were evaluated for per cent root regeneration after 4 weeks of culturing.

\subsection{Preparation of methanol extracts of in vitro grown leaves} and roots

Leaves and roots of in vitro grown plants of $R$. cordifolia were cleaned in sterile distilled water followed by shade drying for 15 days. Further, dried leaves and roots were ground using mortar and pestle. Dried and powdered material was extracted using sonication extraction technique in $100 \%$ methanol for $30 \mathrm{~min}$ in three cycles. Material, thus obtained was stored at $4^{\circ} \mathrm{C}$ until further use (Bhardwaj et al., 2014).

\subsection{GC-MS analysis of MEML}

GC (Shimadzu Gas Chromatography system GC-2010 Plus, Japan) coupled with MS (GC-MS-QP 2010 Ultra) analysis of RUML and RUMR was carried out to decipher the type of phytochemicals accumulated in leaves and roots, respectively. For this, the temperature of injection port was set at $280^{\circ} \mathrm{C}$ whereas, oven temperature was programmed as: initial temperature as $80^{\circ} \mathrm{C}$ with a hold time of $2.0 \mathrm{~min}$ which was further increased at the rate of $4^{\circ} \mathrm{C} / \mathrm{min}$ to $236^{\circ} \mathrm{C}$ with a hold of $5 \mathrm{~min}$. Finally, the temperature was increased at the rate of $5^{\circ} \mathrm{C} / \mathrm{min}$ to $300^{\circ} \mathrm{C}$ and held for 19.0 mins. Helium gas was used as carrier with the flow rate of $1.10 \mathrm{ml} /$ min and split ratio of 1:5. The mass spectrum was recorded at $70 \mathrm{eV}$ with electron ionization (EI) mode. Identification of various components was carried out exclusively by a comparison of their retention time and mass spectral data with the retention time and mass spectral database of Wiley 8 library. Compounds were quantified on the basis of area under the peak and results were presented in terms of percentage area (Bhardwaj et al., 2020).

\subsection{Data analysis}

Statistical analysis of results has been represented in the form of mean \pm standard error. One-way-ANOVA (analysis of variance) with Duncan's multiple range tests was used to determine the significance of obtained results. The probability $(p)$ value $\leq 0.05$ was considered significant for ANOVA and marked correlations among different assays. Results were processed with the help of computer programs, viz., MS Excel (USA) and SPSS v. 17.0 (USA). 
Table 1: Effect of BAP and kinetin on nodal explant

\begin{tabular}{|c|c|c|c|c|}
\hline Sr.No. & Treatment & Medium composition & No. of shoots & Length of shoots \\
\hline 1. & RUB K0A & MS basal medium $+0.0 \mu \mathrm{M} \mathrm{BAP}+0.0 \mu \mathrm{M} \mathrm{KN}$ & $\mathrm{NG}^{\mathrm{a}}$ & $\mathrm{NG}^{\mathrm{a}}$ \\
\hline 2. & RUB K1A & MS basal medium $+0.5 \mu \mathrm{M} \mathrm{BAP}+0.5 \mu \mathrm{M} \mathrm{KN}$ & $22 \pm 0.577^{\mathrm{i}}$ & $2.47 \pm 0.32^{\mathrm{f}}$ \\
\hline 3. & RUB K2A & MS basal medium $+0.5 \mu \mathrm{M} \mathrm{BAP}+1.0 \mu \mathrm{M} \mathrm{KN}$ & $4.67 \pm 0.94^{\mathrm{b}}$ & $0.6 \pm 0.066^{\mathrm{b}, \mathrm{c}, \mathrm{d}}$ \\
\hline 4. & RUB K3A & MS basal medium $+0.5 \mu \mathrm{M} \mathrm{BAP}+2.5 \mu \mathrm{M} \mathrm{KN}$ & $8 \pm 1.154^{\mathrm{c}, \mathrm{d}}$ & $1.37 \pm 0.27^{\mathrm{e}, \mathrm{f}}$ \\
\hline 5. & RUB K4A & MS basal medium $+0.5 \mu \mathrm{M} \mathrm{BAP}+3.0 \mu \mathrm{M} \mathrm{KN}$ & $19.66 \pm 1.45^{\text {g.h,i }}$ & $1.5 \pm 0.360^{\mathrm{f}}$ \\
\hline 6. & RUB K5A & MS basal medium $+0.5 \mu \mathrm{M} \mathrm{BAP}+5.0 \mu \mathrm{M} \mathrm{KN}$ & $20.33 \pm 1.45^{\mathrm{h}, \mathrm{i}}$ & $1.73 \pm 0.176^{\mathrm{f}}$ \\
\hline 7. & RUB K6A & MS basal medium $+1.0 \mu \mathrm{M} \mathrm{BAP}+0.5 \mu \mathrm{M} \mathrm{KN}$ & $12.33 \pm 1.45^{\mathrm{e}}$ & $0.33 \pm 0.12^{\mathrm{a}, \mathrm{b}, \mathrm{c}}$ \\
\hline 8. & RUB K7A & MS basal medium $+1.0 \mu \mathrm{M}$ BAP $+1.0 \mu \mathrm{M} \mathrm{KN}$ & $42.33 \pm 1.45^{\mathrm{k}}$ & $1.53 \pm 0.29^{\mathrm{f}}$ \\
\hline 9. & RUB K8A & MS basal medium $+1.0 \mu \mathrm{M} \mathrm{BAP}+2.5 \mu \mathrm{M} \mathrm{KN}$ & $17.66 \pm 1.45^{\mathrm{f}, \mathrm{g}, \mathrm{h}}$ & $0.63 \pm 0.12^{\mathrm{b}, \mathrm{c}, \mathrm{d}}$ \\
\hline 10 . & RUB K9A & MS basal medium $+1.0 \mu \mathrm{M} \mathrm{BAP}+3.0 \mu \mathrm{M} \mathrm{KN}$ & $8 \pm 1.154^{\mathrm{c}, \mathrm{d}}$ & $0.87 \pm 0.088^{\mathrm{c}, \mathrm{d}, \mathrm{e}}$ \\
\hline 11. & RUBK10A & MS basal medium $+1.0 \mu \mathrm{M} \mathrm{BAP}+5.0 \mu \mathrm{M} \mathrm{KN}$ & $16.67 \pm 0.88^{\mathrm{f}, \mathrm{g}}$ & $0.93 \pm 0.088^{\mathrm{d}, \mathrm{e}}$ \\
\hline 12. & RUBK11A & MS basal medium $+2.5 \mu \mathrm{M} \mathrm{BAP}+0.5 \mu \mathrm{M} \mathrm{KN}$ & $\mathrm{C}^{\mathrm{a}}$ & $\mathrm{C}^{\mathrm{a}}$ \\
\hline 13. & RUBK12A & $\mathrm{MS}$ basal medium $+2.5 \mu \mathrm{M} \mathrm{BAP}+1.0 \mu \mathrm{M} \mathrm{KN}$ & $6.67 \pm 0.88^{\mathrm{b}, \mathrm{c}}$ & $0.2 \pm 0.057^{\mathrm{a}, \mathrm{b}}$ \\
\hline 14. & RUBK13A & MS basal medium $+2.5 \mu \mathrm{M} \mathrm{BAP}+2.5 \mu \mathrm{M} \mathrm{KN}$ & $29.33 \pm 0.88^{\mathrm{j}}$ & $1.53 \pm 0.11^{\mathrm{f}}$ \\
\hline 15. & RUBK14A & MS basal medium $+2.5 \mu \mathrm{M} \mathrm{BAP}+3.0 \mu \mathrm{M} \mathrm{KN}$ & $16 \pm 0.577^{\mathrm{f}}$ & $1.67 \pm 0.088^{\mathrm{f}}$ \\
\hline 16. & RUBK15A & $\mathrm{MS}$ basal medium $+2.5 \mu \mathrm{M} \mathrm{BAP}+5.0 \mu \mathrm{M} \mathrm{KN}$ & $18 \pm 0.577^{\mathrm{f}, \mathrm{g}, \mathrm{h}}$ & $1.67 \pm 0.18^{\mathrm{f}}$ \\
\hline 17. & RUBK16A & MS basal medium $+5.0 \mu \mathrm{M} \mathrm{BAP}+0.5 \mu \mathrm{M} \mathrm{KN}$ & $0^{\mathrm{a}}$ & $0^{\mathrm{a}}$ \\
\hline 18. & RUBK17A & MS basal medium $+5.0 \mu \mathrm{M} \mathrm{BAP}+1.0 \mu \mathrm{M} \mathrm{KN}$ & $10.33 \pm 0.33^{\mathrm{d}, \mathrm{e}}$ & $0.73 \pm 0.12^{\mathrm{b}, \mathrm{c}, \mathrm{d}}$ \\
\hline 19. & RUBK18A & MS basal medium $+5.0 \mu \mathrm{M} \mathrm{BAP}+2.5 \mu \mathrm{M} \mathrm{KN}$ & $12.67 \pm 0.66^{\mathrm{e}}$ & $1.33 \pm 0.088^{\mathrm{e}, \mathrm{f}}$ \\
\hline 20. & RUBK19A & MS basal medium $+5.0 \mu \mathrm{M} \mathrm{BAP}+3.0 \mu \mathrm{M} \mathrm{KN}$ & $17 \pm 0.577^{\mathrm{f}, \mathrm{g}}$ & $0.433 \pm 0.120^{\mathrm{a}, \mathrm{b}, \mathrm{c}, \mathrm{d}}$ \\
\hline
\end{tabular}

Values are means \pm SE of three determinations. The values having different superscript (small alphabet) letters within a column were significantly different $(p \leq 0.05)$; NG- no growth, C-Callus.

Table 2: Effect of BAP, NAA and kinetin on regeneration from leaf explant

\begin{tabular}{|c|c|c|c|c|}
\hline Sr.no. & Treatment & Medium composition & No. of shoots & Length of shoots \\
\hline 1. & RUBNK0A & MS basal medium $+0.0 \mu \mathrm{M} \mathrm{BAP}+0.0 \mu \mathrm{M}$ NAA $+0.0 \mu \mathrm{M} \mathrm{KN}$ & $\mathrm{C}^{\mathrm{a}}$ & $\mathrm{C}^{\mathrm{a}}$ \\
\hline 2. & RUBNK1 A & MS basal medium $+0.5 \mu \mathrm{M} \mathrm{BAP}+0.0 \mu \mathrm{M} \mathrm{NAA}+0.5 \mu \mathrm{M} \mathrm{KN}$ & $2.67 \pm 0.67^{\mathrm{c}}$ & $0.9 \pm 0.26^{\mathrm{b}, \mathrm{c}}$ \\
\hline 3. & RUBNK2A & MS basal medium $+0.5 \mu \mathrm{M} \mathrm{BAP}+1.0 \mu \mathrm{M} \mathrm{NAA}+0.5 \mu \mathrm{M} \mathrm{KN}$ & $4.33 \pm 0.33^{\mathrm{d}}$ & $2.13 \pm 0.35^{\mathrm{f}}$ \\
\hline 4. & RUBNK3A & MS basal medium $+0.5 \mu \mathrm{M} \mathrm{BAP}+3.0 \mu \mathrm{M} \mathrm{NAA}+0.5 \mu \mathrm{M} \mathrm{KN}$ & $2.33 \pm 0 .{ }^{b, c}$ & $1.63 \pm 0.12^{\mathrm{e}}$ \\
\hline 5. & RUBNK4A & MS basal medium $+0.5 \mu \mathrm{M} \mathrm{BAP}+5.0 \mu \mathrm{M} \mathrm{NAA}+0.5 \mu \mathrm{M} \mathrm{KN}$ & $\mathrm{C}^{\mathrm{a}}$ & $\mathrm{C}^{\mathrm{a}}$ \\
\hline 6. & RUBNK5A & MS basal medium $+1.0 \mu \mathrm{M} \mathrm{BAP}+0.0 \mu \mathrm{M} \mathrm{NAA}+1.0 \mu \mathrm{M} \mathrm{KN}$ & $8.33 \pm 0.88^{\mathrm{f}}$ & $1.5 \pm 0.17^{\mathrm{e}}$ \\
\hline 7. & RUBNK6A & MS basal medium $+1.0 \mu \mathrm{M} \mathrm{BAP}+1.0 \mu \mathrm{M} \mathrm{NAA}+1.0 \mu \mathrm{M} \mathrm{KN}$ & $2.67 \pm 0.33^{c}$ & $2.17 \pm 0.24^{\mathrm{f}}$ \\
\hline 8. & RUBNK7A & MS basal medium $+1.0 \mu \mathrm{M} \mathrm{BAP}+3.0 \mu \mathrm{M} \mathrm{NAA}+5.0 \mu \mathrm{M} \mathrm{KN}$ & $\mathrm{C}^{\mathrm{a}}$ & $\mathrm{C}^{\mathrm{a}}$ \\
\hline 9. & RUBNK8A & MS basal medium $+1.0 \mu \mathrm{M} \mathrm{BAP}+5.0 \mu \mathrm{M} \mathrm{NAA}+1.0 \mu \mathrm{M} \mathrm{KN}$ & $\mathrm{C}^{\mathrm{a}}$ & $\mathrm{C}^{\mathrm{a}}$ \\
\hline 10. & RUBNK9A & MS basal medium $+2.5 \mu \mathrm{M} \mathrm{BAP}+0.0 \mu \mathrm{M} \mathrm{NAA}+2.5 \mu \mathrm{M} \mathrm{KN}$ & $1.33 \pm 0.33^{\mathrm{a}, \mathrm{b}}$ & $1.37 \pm 0.29 \mathrm{~d}, \mathrm{e}$ \\
\hline 11. & RUBNK10A & MS basal medium $+2.5 \mu \mathrm{M} \mathrm{BAP}+1.0 \mu \mathrm{M} \mathrm{NAA}+2.5 \mu \mathrm{M} \mathrm{KN}$ & $2.67 \pm 0.57^{\mathrm{c}}$ & $0.467 \pm 0.25^{\mathrm{a}, \mathrm{b}}$ \\
\hline 12. & RUBNK11A & MS basal medium $+2.5 \mu \mathrm{M}$ BAP $+3.0 \mu \mathrm{M} \mathrm{NAA}+2.5 \mu \mathrm{M} \mathrm{KN}$ & $\mathrm{C}^{\mathrm{a}}$ & $\mathrm{C}^{\mathrm{a}}$ \\
\hline 13. & RUBNK12A & MS basal medium $+2.5 \mu \mathrm{M} \mathrm{BAP}+5.0 \mu \mathrm{M} \mathrm{NAA}+2.5 \mu \mathrm{M} \mathrm{KN}$ & $\mathrm{C}^{\mathrm{a}}$ & $\mathrm{C}^{\mathrm{a}}$ \\
\hline 14. & RUBNK13A & MS basal medium $+3.0 \mu \mathrm{M} \mathrm{BAP}+0.0 \mu \mathrm{M} \mathrm{NAA}+3.0 \mu \mathrm{M} \mathrm{KN}$ & $1.33 \pm 0.577^{\mathrm{a}, \mathrm{b}}$ & $0.76 \pm 0.055^{\mathrm{b}, \mathrm{c}}$ \\
\hline 15. & RUBNK14A & MS basal medium $+3.0 \mu \mathrm{M} \mathrm{BAP}+1.0 \mu \mathrm{M} \mathrm{NAA}+3.0 \mu \mathrm{M} \mathrm{KN}$ & $6.67 \pm 0.88^{\mathrm{e}}$ & $0.87 \pm 0.26^{\mathrm{b}, \mathrm{c}, \mathrm{d}}$ \\
\hline 16. & RUBNK15A & MS basal medium $+3.0 \mu \mathrm{M} \mathrm{BAP}+3.0 \mu \mathrm{M} \mathrm{NAA}+3.0 \mu \mathrm{M} \mathrm{KN}$ & $1.66 \pm 0.33^{\mathrm{b}, \mathrm{c}}$ & $1.13 \pm 0.12^{\mathrm{c}, \mathrm{d}, \mathrm{e}}$ \\
\hline 17. & RUBNK16A & MS basal medium $+3.0 \mu \mathrm{M} \mathrm{BAP}+5.0 \mu \mathrm{M} \mathrm{NAA}+3.0 \mu \mathrm{M} \mathrm{KN}$ & $\mathrm{C}^{\mathrm{a}}$ & $\mathrm{C}^{\mathrm{a}}$ \\
\hline
\end{tabular}

Values are means \pm SE of three determinations. The values having different superscript (small alphabet) letters within a column were significantly different $(p \leq 0.05)$; C-Callus. 
Table 3: Rooting of in vitro regenerated shoots

\begin{tabular}{|c|l|c|}
\hline Sr.No. & Auxins & Percent rooting \\
\hline 1. & $0.05 \mathrm{NAA}$ & $85 \pm 1.73$ \\
\hline 2. & $0.01 \mathrm{NAA}$ & $99.67 \pm 0.33$ \\
\hline 3. & $0.02 \mathrm{NAA}$ & $95 \pm 1.154$ \\
\hline 4. & $0.05 \mathrm{IBA}$ & $74 \pm 1.45$ \\
\hline 5. & $0.01 \mathrm{IBA}$ & $81 \pm 0.577$ \\
\hline 6. & $0.02 \mathrm{IBA}$ & $73.66 \pm 0.88$ \\
\hline
\end{tabular}

Values are means \pm SE of three determinations.

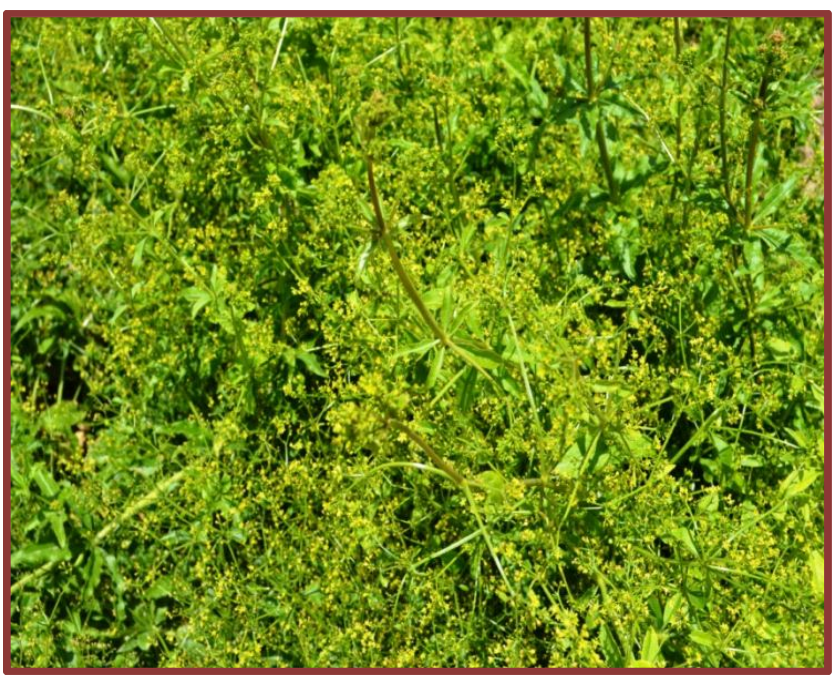

Figure 1: Rubia cordifolia growing in its natural habitat.

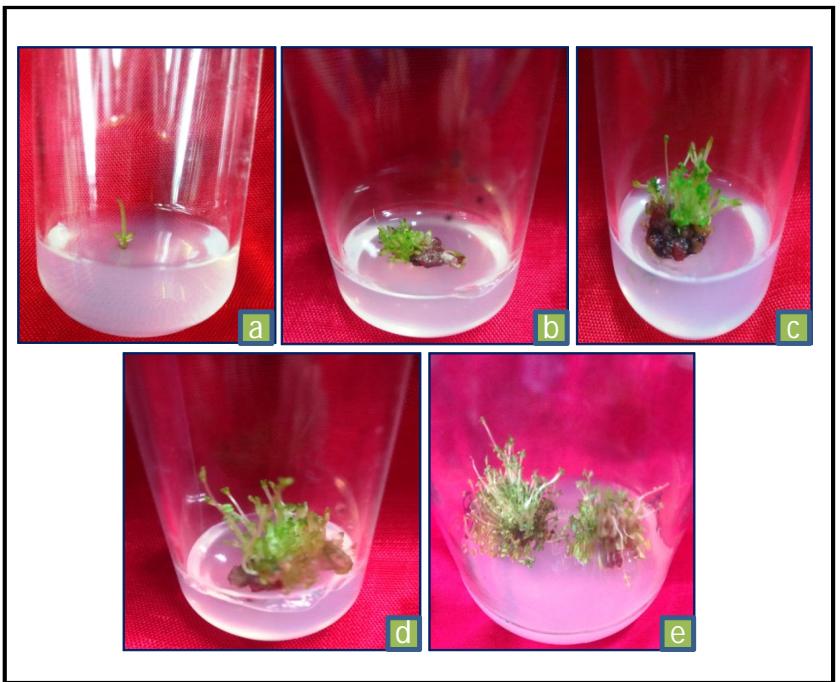

Figure 2: (a) Nodal explant inoculated on MS media

(b) Initiation of shooting (15 days old)

(c) Multiple shoot induction

(d) Regeneration of new shoots

(e) In vitro proliferated shoots and roots (40 days).

\section{Results}

3.1 Multiple shoots induction from nodal explants

A total of 20 different combinations of BAP and $\mathrm{KN}$ were investigated for effective shoot regeneration from nodal explant keeping basal MS media as control (Table 1). Equal concentrations of both hormones were found optimum for effective shoots regeneration. Maximum number of shoots $(42.33 \pm 1.43)$ were found to develop on RUBK7 media containing $1.0 \mu \mathrm{M}$ concentration of each of hormone whereas shoots with maximal length $(2.47 \pm 0.32)$ were obtained in RUBK1 medium $(2.5 \mu \mathrm{M}$ BAP and $2.5 \mu \mathrm{M} \mathrm{KN})$ (Table 1, Figure 2).

\subsection{Multiple shoots induction from leaf explants}

Surface sterilized leaves were cut with sterile scalpel blade and placed horizontally on medium containing 16 different concentration of NAA $(\mu \mathrm{M})$ with BAP $(\mu \mathrm{M})$ and $\mathrm{KN}(\mu \mathrm{M})$ for effective organ differentiation. All the explants were found to induce callus, however duration of callus formation varied in different concentrations used (Table 2). Maximum number of shoots $(8.33 \pm 0.88)$ were found to grow in RUBNK5 medium containing MS media supplemented with $1.0 \mu \mathrm{M}$ concentration of each of BAP and NAA. Whereas shoots with maximum length were observed in MS medium containing 1.0 $\mu \mathrm{M}$ of each of BAP, KN and NAA. Further, a higher concentration of NAA in comparison to both KN and BAP were found to show no effect on organ differentiation in callus (Table 2, Figure 3).

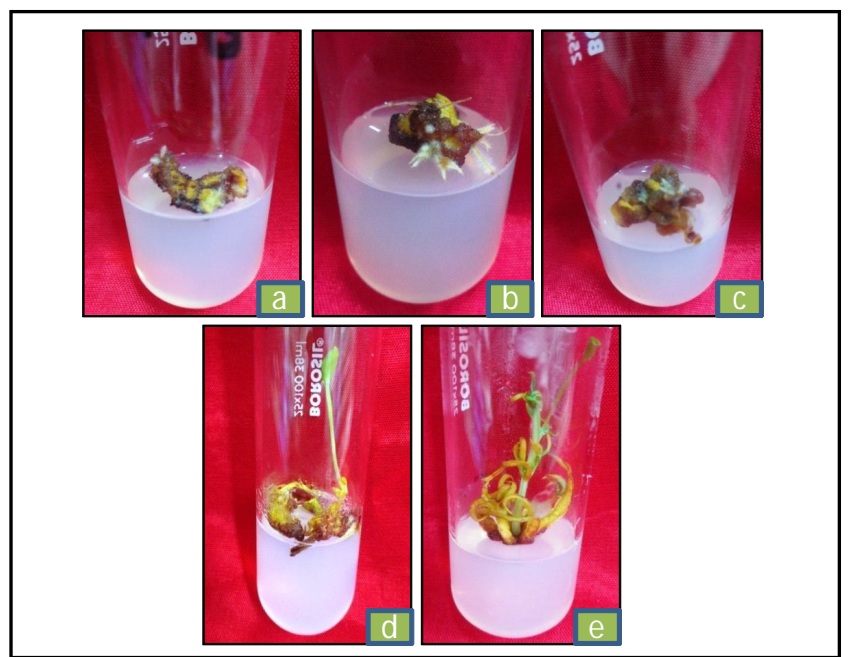

Figure 3: (a) Leaf explant inoculated on MS media, (b) In vitro root proliferation (25 days old), (c) In vitro shoot proliferation, (d) Regeneration of new shoots from nodal explant and (e) In vitro development of complete plant (40 days).

\subsection{Rooting of in vitro grown shoots}

In vitro grown shoots were cultured on MS medium supplemented with different concentrations of NAA and IBA (Table 3). Maximum healthy and vigorous root system was found to develop after two weeks of inoculation after which no noticeable changes in development was observed. Maximum per cent root regeneration $(99.67 \pm 0.33)$ was observed in $0.1 \mathrm{mg} / 1 \mathrm{NAA}$, whereas in case of NAA, $81 \pm 0.577 \%$ root regeneration was found to develop in 0.1 $\mathrm{mg} / \mathrm{l}$ IBA concentration (Table 3). 
Table 4: Compounds identified in GC-MS analysis of RUML

\begin{tabular}{|c|c|c|c|c|c|c|}
\hline Sr. No. & Name & Formula & SI & $\%$ Area & Medicinal use & References \\
\hline 1. & Octyl 2-Methylpropanoate & $\mathrm{C}_{12} \mathrm{H}_{24} \mathrm{O}_{2}$ & 84 & 0.95 & Antiinflammatory and antibacterial & Hussein et al., 2016 \\
\hline 2. & Neophytadiene & $\mathrm{C}_{20} \mathrm{H}_{38}$ & 95 & 11.82 & $\begin{array}{l}\text { Antibacterial, skin diseases, } \\
\text { rheumatism }\end{array}$ & Singh et al., 2012 \\
\hline 3. & $\begin{array}{l}3,7,11,15 \text {-Tetramethyl-2- } \\
\text { hexadecen-1-ol }\end{array}$ & $\mathrm{C}_{20} \mathrm{H}_{40} \mathrm{O}$ & 90 & 4.31 & $\begin{array}{l}\text { Anxiolytic, antioxidant, autophagy- } \\
\text { anti-inflammatory, immune-modu- } \\
\text { lating, and antimicrobial effects }\end{array}$ & Islam et al., 2016 \\
\hline 4. & $\begin{array}{l}\text { Heptadecanoic Acid, methyl } \\
\text { Ester }\end{array}$ & $\mathrm{C}_{18} \mathrm{H}_{36} \mathrm{O}_{2}$ & 91 & 1.00 & Hypoglycaemic, antioxidantactivities & Babu et al., 2017 \\
\hline 5. & $\begin{array}{l}\text { 6-Octadecenoic acid, methyl } \\
\text { ester }\end{array}$ & $\mathrm{C}_{19} \mathrm{H}_{36} \mathrm{O}_{2}$ & 84 & 3.64 & Antioxidant, anticancer & Belakhdar et al., 2015 \\
\hline 6. & Phytol & $\mathrm{C}_{20} \mathrm{H}_{40} \mathrm{O}$ & 87 & 5.61 & $\begin{array}{l}\text { Antioxidant, hypocholestrolemia, } \\
\text { nematicide, hemolytic, }\end{array}$ & Sharma et al., 2015. \\
\hline 7. & $\begin{array}{l}\text { 1,2-Benzenedicarboxylic Acid, } \\
\text { Dioctyl ester }\end{array}$ & $\mathrm{C}_{24} \mathrm{H}_{38} \mathrm{O} 4$ & 82 & 0.86 & Antimicrobial activity & $\begin{array}{l}\text { Osuntokun and } \\
\text { Gamberini, } 2019 .\end{array}$ \\
\hline 8. & 9-Octadecenamide & $\mathrm{C}_{18} \mathrm{H}_{35} \mathrm{NO}$ & 91 & 18.85 & $\begin{array}{l}\text { Anti-inflammatory activity and } \\
\text { antibacterial activity }\end{array}$ & Hussein et al., 2016 \\
\hline 9. & Squalene & $\mathrm{C}_{30} \mathrm{H}_{5} \mathrm{O}$ & 95 & 9.96 & Antioxidant and anti tumouractivities & Haung et al., 2009 \\
\hline 10 . & Pentadecanone & $\mathrm{C}_{15} \mathrm{H}_{30} \mathrm{O}$ & 83 & 2.05 & Antioxidant and antibacterial activity & Bhardwaj et al., 2014 \\
\hline 11. & alpha-Tocoferol & $\mathrm{C}_{29} \mathrm{H}_{50} \mathrm{O}_{2}$ & 88 & 7.18 & $\begin{array}{l}\text { Antioxidant and anti-inflammatory } \\
\text { activities }\end{array}$ & Cassano et al., 2015 \\
\hline 12. & Stigmast-5-en-3-ol & $\mathrm{C}_{29} \mathrm{H}_{50} \mathrm{O}$ & 81 & 4.87 & Antidiabetic agent & Sujatha et al., 2015 \\
\hline 13. & Gamma-Sitosterol & $\mathrm{C}_{29} \mathrm{H}_{50} \mathrm{O}$ & 81 & 3.80 & $\begin{array}{l}\text { Antihypercholesterolemic, antiviral } \\
\text { (influenza), antiinflammatory, } \\
\text { antiacne, antiprotozoal (leishmania), } \\
\text { antibacterial }\end{array}$ & Adnan et al., 2019 \\
\hline 14. & [1,1'-Bicyclohexyl]-2,2'-diol & $\mathrm{C}_{12} \mathrm{H}_{22} \mathrm{O}_{2}$ & 77 & 0.97 & No reported biological activity & \\
\hline 15 . & $\begin{array}{l}\text { Cyclopenta }[\mathrm{C}] \text { Pyran-3(1H) } \\
\text {-one, Hexahydro-4,7- } \\
\text { Dimethyl- }\end{array}$ & $\mathrm{C}_{10} \mathrm{H}_{16} \mathrm{O}_{2}$ & 74 & 1.40 & No reported biological activity & \\
\hline 16. & 4-Tridecanol & $\mathrm{C}_{13} \mathrm{H}_{28} \mathrm{O}$ & 79 & 1.52 & $\begin{array}{l}\text { Esters for synthetic lubricants; } \\
\text { detergents; antifoam agent }\end{array}$ & Lewis, 2001 \\
\hline 17. & $\begin{array}{l}\text { 3,3-Dimethylbutyric acid } \\
\text { 2,2,3,3,4,4,4-heptafluorobutyl } \\
\text { ester }\end{array}$ & $\mathrm{C}_{10} \mathrm{H}_{13} \mathrm{~F}_{7} \mathrm{O}_{2}$ & 67 & 0.67 & No reported biological activity & \\
\hline 18. & $\begin{array}{l}\text { N-[2-(4-Benzenesulfonyl- } \\
\text { Piperazin-1-YL)-Ethyl]-N' } \\
\text {-(4-Methyl-Benzyl)-Oxalamide }\end{array}$ & $\mathrm{C}_{22} \mathrm{H}_{28} \mathrm{~N}_{4} \mathrm{O}_{4} \mathrm{~S}$ & 68 & 1.27 & No reported biological activity & \\
\hline 19. & $\begin{array}{l}\text { Erythro-9,10-dibromopen- } \\
\text { tacosane }\end{array}$ & $\mathrm{C}_{25} \mathrm{H}_{50} \mathrm{Br}_{2}$ & 65 & 1.40 & No reported biological activity & \\
\hline 20. & 2,3,4-trimethyl-1-pentanol & $\mathrm{C}_{8} \mathrm{H}_{18} \mathrm{O}$ & 75 & 0.29 & No reported biological activity & \\
\hline
\end{tabular}


Table 5: Compounds identified in GC-MS analysis of RUMR

\begin{tabular}{|c|c|c|c|c|c|c|}
\hline Sr.No. & Name & Formula & SI & \% Area & Medicinal use & References \\
\hline 1. & Neophytadiene & $\mathrm{C}_{20} \mathrm{H}_{38}$ & 84 & 1.79 & Antibacterial, skin diseases, rheumatism & Singh et al., 2012 \\
\hline 2. & 2-Decen-1-ol & $\mathrm{C}_{10} \mathrm{H}_{20} \mathrm{O}$ & 83 & 0.70 & & \\
\hline 3. & $\begin{array}{l}\text { Tetradecanoic acid, 12- } \\
\text { methyl-, methyl ester }\end{array}$ & $\mathrm{C}_{16} \mathrm{H}_{32} \mathrm{O}_{2}$ & 89 & 1.95 & No reported biological activity & \\
\hline 4. & $\begin{array}{l}\text { Cyclobutene, 1-Methyl- } \\
\text { 3-Propyl }\end{array}$ & $\mathrm{C}_{8} \mathrm{H}_{14}$ & 81 & 0.31 & No reported biological activity & \\
\hline 5. & $\begin{array}{l}\text { 7-Hexadecenoic acid, } \\
\text { methyl ester }\end{array}$ & $\mathrm{C}_{17} \mathrm{H}_{32} \mathrm{O}_{2}$ & 85 & 2.98 & Antibacterial and antifungal & $\begin{array}{l}\text { Chandrasekaran et al., } \\
2011\end{array}$ \\
\hline 6. & $\begin{array}{l}\text { 9-Octadecenoic acid (Z)-, } \\
\text { methyl ester }\end{array}$ & $\mathrm{C}_{19} \mathrm{H}_{36} \mathrm{O}_{2}$ & 83 & 26.41 & $\begin{array}{l}\text { Hypocholesterolemic, 5-alpha } \\
\text { reductase inhibitor, anemiagenic } \\
\text { insectifuge, flavor }\end{array}$ & Gnana et al., 2018 \\
\hline 7. & $\begin{array}{l}\text { Heptadecanoic Acid, Methyl } \\
\text { Ester }\end{array}$ & $\mathrm{C}_{18} \mathrm{H}_{36} \mathrm{O}_{2}$ & 89 & 1.09 & Hypoglycaemic, antioxidantactivities & Babu et al., 2017 \\
\hline 8. & $\begin{array}{l}\text { 1,2-Benzenedicarboxylic Acid, } \\
\text { Dioctyl Ester }\end{array}$ & $\mathrm{C}_{24} \mathrm{H}_{38} \mathrm{O}_{4}$ & 88 & 1.09 & Antibacterial & Ajoke et al., 2015) \\
\hline 9. & Squalene & $\mathrm{C}_{30} \mathrm{H}_{50}$ & 95 & 11.22 & Antioxidant and antitumour activities & Haung et al., 2009 \\
\hline 10 . & dl-.alpha.-Tocopherol & $\mathrm{C}_{29} \mathrm{H}_{50} \mathrm{O}_{2}$ & 88 & 1.87 & $\begin{array}{l}\text { Antioxidant and antiinflammat } \\
\text { oryactivities }\end{array}$ & Cassano et al., 2015 \\
\hline 11. & $\begin{array}{l}\text { Adenosine, N6-phenylacetic } \\
\text { acid }\end{array}$ & $\mathrm{C}_{18} \mathrm{H}_{19} \mathrm{~N}_{5} \mathrm{O}_{6}$ & 74 & 33.05 & & \\
\hline 12. & Cyclohexaneethanol & $\mathrm{C}_{8} \mathrm{H}_{16} \mathrm{O}$ & 79 & 1.02 & Perfuming and flavouring agents & Larranaga et al., 2016 \\
\hline 13. & {$[1,1$ '-Bicyclohexyl]-2,2'-Diol } & $\mathrm{C}_{12} \mathrm{H}_{22} \mathrm{O}_{2}$ & 78 & 0.92 & No reported biological activity & \\
\hline 14. & $\begin{array}{l}\text { 2H-Pyran, tetrahydro-4- } \\
\text { methylene- }\end{array}$ & $\mathrm{C}_{6} \mathrm{H}_{10} \mathrm{O}$ & 69 & 0.36 & No reported biological activity & \\
\hline 15 . & Phosphinous chloride & $\mathrm{C}_{5} \mathrm{H}_{11} \mathrm{C}_{12} \mathrm{P}$ & 70 & 0.65 & No reported biological activity & \\
\hline 16 . & $\begin{array}{l}\text { Cyclopentaneethanol, } 2- \\
\text { (Hydroxymethyl)-, }\end{array}$ & $\mathrm{C}_{8} \mathrm{H}_{16} \mathrm{O}_{2}$ & 75 & 0.84 & No reported biological activity & \\
\hline 17. & $\begin{array}{l}\text { 1H-Imidazole, 4,5-dihydro- } \\
\text { 2,4-dimethyl }\end{array}$ & $\mathrm{C}_{5} \mathrm{H}_{10} \mathrm{~N}_{2}$ & 71 & 0.97 & No reported biological activity & \\
\hline 19. & $\begin{array}{l}\text { 3,3-dimethylbutyric acid, 2,2, } \\
\text { 3,3,4,4,4-heptafluorobutyl } \\
\text { ester }\end{array}$ & $\mathrm{C}_{10} \mathrm{H}_{13} \mathrm{~F}_{7} \mathrm{O}_{2}$ & 72 & 0.63 & No reported biological activity & \\
\hline 20. & $\begin{array}{l}\text { N-[2-(4-Benzenesulfonyl- } \\
\text { Piperazin-1-YL)-Ethyl]-N'- } \\
\text { (4-Methyl-Benzyl)-Oxalamide }\end{array}$ & $\mathrm{C}_{22} \mathrm{H}_{28} \mathrm{~N}_{4} \mathrm{O}_{4} \mathrm{~S}$ & 73 & 0.84 & No reported biological activity & \\
\hline
\end{tabular}

Table 6: Compounds identified in both extracts along with CAS no and structures

\begin{tabular}{|c|l|c|l|l|}
\hline Sr. No. & CAS & Retention time & Name & Structure \\
\hline 1. & $109-15-9$ & 20.229 & Octyl 2-methylpropanoate & CCCCCCCCOC $(=\mathrm{O}) \mathrm{C}(\mathrm{C}) \mathrm{C}$ \\
\hline 2. & $504-96-1$ & 21.084 & Neophytadiene & CC $(\mathrm{C}) \mathrm{CCCC}(\mathrm{C}) \mathrm{CCCC}(\mathrm{C}) \mathrm{CCCC}(=\mathrm{C}) \mathrm{C}=\mathrm{C}$ \\
\hline 3. & $102608-53-7$ & 21.507 & $3,7,11,15$-tetramethyl-2-hexadecen-1-ol & CC $(\mathrm{C}) \mathrm{CCCC}(\mathrm{C}) \mathrm{CCCC}(\mathrm{C}) \mathrm{CCCC}(=\mathrm{CCO}) \mathrm{C}$ \\
\hline 4. & $1731-92-6$ & 22.604 & Heptadecanoic acid, methyl ester & CCCCCCCCCCCCCCC $(=\mathrm{O}) \mathrm{OC}$ \\
\hline 5. & $2777-58-4$ & 25.379 & 6-Octadecenoic acid, methyl ester & CCCCCCCCCCC=CCCCC $(=\mathrm{O}) \mathrm{OC}$ \\
\hline 6. & $150-86-7$ & 25.560 & Phytol & CC $(\mathrm{C}) \mathrm{CCCC}(\mathrm{C}) \mathrm{CCC}(\mathrm{C}) \mathrm{CCCC}(=\mathrm{CCO}) \mathrm{C}$ \\
\hline 7. & $117-84-0$ & 32.756 & 1,2-Benzenedicarboxylic acid, dioctyl ester & $\begin{array}{l}\mathrm{CCCCCCCCCCC} 1=\mathrm{C}(\mathrm{C}(=\mathrm{CC}=\mathrm{C} 1) \mathrm{C}(=\mathrm{O}) \\
\text { OCCCCCCC }(=\mathrm{O}) \mathrm{OCCCCCCC}\end{array}$ \\
\hline 8. & $301-02-0$ & 37.453 & 9-Octadecenamide & CCCCCCCCC=CCCCCCCC $(=\mathrm{O}) \mathrm{N}$ \\
\hline
\end{tabular}




\begin{tabular}{|c|c|c|c|c|}
\hline 9. & $111-02-4$ & 37.805 & Squalene & $\begin{array}{l}\mathrm{CC}(=\mathrm{CCCC}(=\mathrm{CCCC}(=\mathrm{CCCC}=\mathrm{C}(\mathrm{C}) \mathrm{CCC} \\
=\mathrm{C}(\mathrm{C}) \mathrm{CCC}=\mathrm{C}(\mathrm{C}) \mathrm{C}) \mathrm{C}) \mathrm{C}) \mathrm{C}\end{array}$ \\
\hline 10 & $2765-11-9$ & 38.203 & Pentadecanal & $\mathrm{CCCCCCCCCCCCCCC}=\mathrm{O}$ \\
\hline 11. & $59-02-9$ & 41.399 & alpha-tocoferol & $\begin{array}{l}\mathrm{CC} 1=\mathrm{C}(\mathrm{C} 2=\mathrm{C}(\mathrm{CCC}(\mathrm{O} 2)(\mathrm{C}) \mathrm{CCCC}(\mathrm{C}) \mathrm{CCCC} \\
(\mathrm{C}) \mathrm{CCCC}(\mathrm{C}) \mathrm{C}) \mathrm{C}(=\mathrm{C} 1 \mathrm{O}) \mathrm{C}) \mathrm{C}\end{array}$ \\
\hline 12. & $17385-36-3$ & 24.825 & [1,1'-bicyclohexyl]-2,2'-diol & $\mathrm{C} 1 \mathrm{CC}(\mathrm{CCC} 1 \mathrm{C} 2 \mathrm{CCC}(\mathrm{CC} 2) \mathrm{O}) \mathrm{O}$ \\
\hline 13. & $485-43-8$ & 26.748 & $\begin{array}{l}\text { Cyclopenta[C]pyran-3(1H)-one, } \\
\text { hexahydro-4,7-dimethyl-, }\end{array}$ & $\mathrm{CC} 1 \mathrm{CCC} 2 \mathrm{C} 1 \mathrm{COC}(=\mathrm{O}) \mathrm{C} 2 \mathrm{C}$ \\
\hline 14. & $26215-92-9$ & 28.274 & 4-tridecanol & $\mathrm{CCCCCCCCCC}(\mathrm{CCC}) \mathrm{O}$ \\
\hline 15 . & $0-00-0$ & 29.064 & $\begin{array}{l}\text { 3,3-dimethylbutyric acid } 2,2,3,3,4,4,4 \\
\text {-heptafluorobutyl ester }\end{array}$ & $\operatorname{CCCCCCOC}(=\mathrm{O}) \mathrm{C}(\mathrm{C}(\mathrm{C}(\mathrm{F})(\mathrm{F}) \mathrm{F})(\mathrm{F}) \mathrm{F})(\mathrm{F}) \mathrm{F}$ \\
\hline 16. & $0-00-0$ & 36.449 & $\begin{array}{l}\text { N-[2-(4-benzenesulfonyl-piperazin-1- } \\
\text { YL)-ethyl]-N' -(4-methyl-benzyl)- } \\
\text { oxalamide }\end{array}$ & $\begin{array}{l}\mathrm{CCNS}(=\mathrm{O})(=\mathrm{O}) \mathrm{C} 1=\mathrm{CC}=\mathrm{CC}(=\mathrm{C} 1) \\
\mathrm{C}(=\mathrm{O}) \mathrm{NC} 2=\mathrm{CC}=\mathrm{C}(\mathrm{C}=\mathrm{C} 2) \mathrm{CN} 3 \mathrm{CCCC} \\
(\mathrm{C} 3) \mathrm{C}(=\mathrm{O}) \mathrm{N}\end{array}$ \\
\hline 17. & 59907-02-7 & 41.625 & Erythro-9,10-dibromopentacosane & $\begin{array}{l}\mathrm{CCCCCCCCCCCCCCCC}(\mathrm{C}(\mathrm{CCCCC} \\
\mathrm{CCC}) \mathrm{Br}) \mathrm{Br}\end{array}$ \\
\hline 18. & $83-48-7$ & 42.827 & Stigmasterol & $\begin{array}{l}\mathrm{CCC}(\mathrm{C}=\mathrm{CC}(\mathrm{C}) \mathrm{C} 1 \mathrm{CCC} 2 \mathrm{C} 1(\mathrm{CCC} 3 \mathrm{C} 2 \mathrm{CC} \\
=\mathrm{C} 4 \mathrm{C} 3(\mathrm{CCC}(\mathrm{C} 4) \mathrm{O}) \mathrm{C}) \mathrm{C}) \mathrm{C}(\mathrm{C}) \mathrm{C}\end{array}$ \\
\hline 19. & $83-47-7$ & 43.610 & Gamma-sitosterol & $\begin{array}{l}\mathrm{CCC}(\mathrm{CCC}(\mathrm{C}) \mathrm{C} 1 \mathrm{CCC} 2 \mathrm{C} 1(\mathrm{CCC} 3 \mathrm{C} 2 \mathrm{CC} \\
=\mathrm{C} 4 \mathrm{C} 3(\mathrm{CCC}(\mathrm{C} 4) \mathrm{O}) \mathrm{C}) \mathrm{C}) \mathrm{C}(\mathrm{C}) \mathrm{C}\end{array}$ \\
\hline 20. & $2438-20-2$ & 29.747 & 1-Butanol,2-methyl,propanoate & $\mathrm{CCC}(\mathrm{C}) \mathrm{COC}(=\mathrm{O}) \mathrm{CC}$ \\
\hline 21. & $22104-80-9$ & 21.508 & 2-Decen-1-ol & $\mathrm{CCCCCCCC}=\mathrm{CCO}$ \\
\hline 22. & $5129-66-8$ & 22.604 & Tetradecanoic acid, 12-methyl-, methyl ester & $\operatorname{CCC}(\mathrm{C}) \operatorname{CCCCCCCCCCC}(=\mathrm{O}) \mathrm{OC}$ \\
\hline 23 & $122699-82-5$ & 25.263 & Cyclobutene, 1-methyl-3-propyl & $\operatorname{CCCC} 1 \mathrm{CCCC}(\mathrm{C} 1) \mathrm{C}$ \\
\hline 24. & $56875-67-3$ & 25.375 & 7-Hexadecenoic acid, methyl ester & $\mathrm{CCCCCCCCC}=\mathrm{CCCCCCC}(=\mathrm{O}) \mathrm{OC}$ \\
\hline 25. & $112-62-9$ & 25.541 & 9-Octadecenoic acid (Z)-, methyl ester & $\operatorname{CCCCCCCCC}=\operatorname{CCCCCCCCC}(=\mathrm{O}) \mathrm{OC}$ \\
\hline 26. & $96760-57-5$ & 14.593 & Adenosine, N6-phenylacetic acid & $\begin{array}{l}\mathrm{C} 1=\mathrm{CC}(=\mathrm{CC}=\mathrm{C} 1 \mathrm{CC}(=\mathrm{O}) \mathrm{O}) \mathrm{NC} 2= \\
\mathrm{C} 3 \mathrm{C}(=\mathrm{NC}=\mathrm{N} 2) \mathrm{N}(\mathrm{C}=\mathrm{N} 3) \mathrm{C} 4 \mathrm{C}(\mathrm{C}(\mathrm{C}(\mathrm{O} 4) \\
\mathrm{CO}) \mathrm{O}) \mathrm{O}\end{array}$ \\
\hline 27. & $4442-79-9$ & 21.822 & Cyclohexane ethanol & $\mathrm{C} 1 \mathrm{CCC}(\mathrm{CC} 1) \mathrm{CCO}$ \\
\hline 28. & $36838-71-8$ & 25.472 & 2H-Pyran, tetrahydro-4-methylene- & CC1CCOCC1 \\
\hline 29. & $78055-63-7$ & 26.107 & Phosphinous chloride & $\mathrm{CCCC}(\mathrm{C}) \mathrm{P}(\mathrm{Cl}) \mathrm{Cl}$ \\
\hline 30 & $15773-82-7$ & 26.739 & Cyclopentaneethanol, 2-(hydroxymethyl)-, & $\operatorname{CCCCCCCC}(=\mathrm{O}) \mathrm{O}$ \\
\hline 31. & 28.288 & $930-61-0$ & 1H-Imidazole, 4,5-dihydro-2,4-dimethyl & $\mathrm{CC} 1 \mathrm{CN}=\mathrm{C}(\mathrm{N} 1) \mathrm{C}$ \\
\hline
\end{tabular}

\subsection{GC-MS analysis}

GC-MS chromatogram of methanolic extract of in vitro grown leaves (RUML) recorded a total of 20 peaks corresponding to bioactive phytoconstituents by relating their retention time, peak area and height with Wiley 8 library (Figure 4A-B, Table 4). Phytoconstituents identified in RUML were Octyl 2-methyl propanoate, neophytadiene, 3,7,11,15-tetramethyl-2-hexadecen-1-ol, heptadecanoic acid, methyl ester, 6-octadecenoic acid, methyl ester, phytol, 1,2-benzenedicarboxylic acid, dioctyl ester, 9octadecenamide, squalene, pentadecanone, alpha-tocoferol, stigmast5-en-3-ol, gamma-sitosterol, [1,1'-bicyclohexyl]-2,2'-diol, cyclopenta[c]pyran-3(1h)-one, hexahydro-4,7-dimethyl-,4tridecanol, 3,3-dimethylbutyric acid 2,2,3,3,4,4,4-heptafluorobutyl ester, n-[2-(4-benzen esulfon yl-piperazin-1-yl)-ethyl]-n' -(4- methyl-benzyl)-oxalamide, erythro-9,10-dibromopentacosane, and 2,3,4-trimethyl-1-pentanol (Table 4). Nine identified phytoconstituents were found with S.I. score $>80$. Further, GC-MS analysis of methanolic extract of in vitro grown roots (RUMR) also recorded characteristic 19 peaks corresponding to different phytocomponents with various reported biological activities (Table 5; Figures 5A-B). It included neophytadiene, 2-decen-1-ol, tetradecanoic acid, 12-methyl-, methyl ester, cyclobutene, 1-methyl3-propyl, 7-hexadecenoic acid, methyl ester, 9-octadecenoic acid (Z)-, methyl ester, heptadecanoic acid, methyl ester, 1,2benzenedicarboxylic acid, dioctyl ester, squalene, dl-.alpha.tocopherol, adenosine, N6-phenylacetic acid, cyclohexane ethanol, [1,1'-bicyclohexyl]-2,2'-diol, 2H-pyran, tetrahydro-4-methylene-, phosphinous chloride, cyclopentaneethanol, 2-(hydroxymethyl)-, 1H-imidazole, 4,5-dihydro-2,4-dimethyl, 3,3-dimethylbutyric acid, 
2,2,3,3,4,4,4-heptafluorobutyl ester and N-[2-(4-benzenesulfonylpiperazin-1-yl)-ethyl]-n'-(4-methyl-benzyl)-oxalamide. Out of 19 compounds observed in RUMR, 10 were found with S.I. value >
$80 \%$ (Table 5) . Further, 8 compounds were observed common in both samples. Structure of the all detected 40 compounds are given in Table 6 with their CAS no.

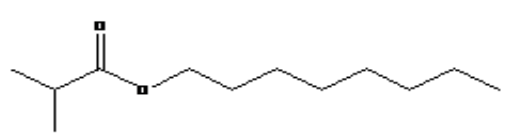

Octyl-2-methyl propanate

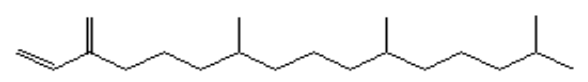

Neophytadiene

事

3,7,11,15- Tetramethyl-2-hexadecen-1-ol

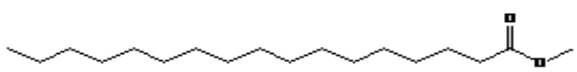

Heptadecanoic acid, Methyl Ester

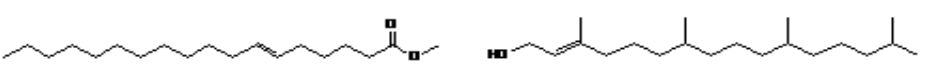

6-Octadecanoic acid, Methyl Ester

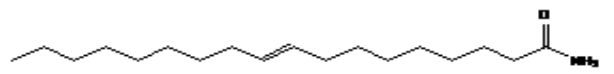

9-Octadecenamide

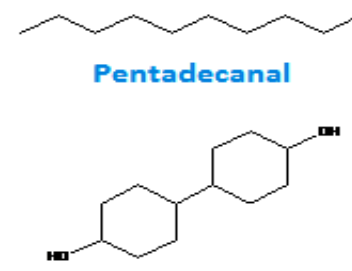

[1,1'-Bicyclọhexyl]-2,2'-diol

Phytol

Cyclopenta[c]Pyran-3(1H)-one,

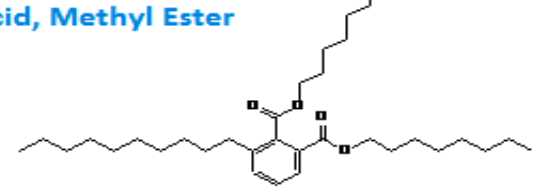

1,2-Benzene dicarboxyllic acid, Dioctylester

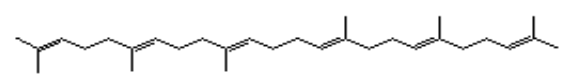

Squalene

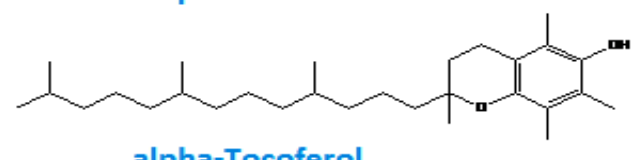

alpha-Tocoferol

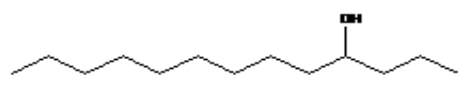

4-Tridecanol Hexahydro-4,7-Dimethyl

Figure 4A: Identified compunds in GC-MS profile of in vitro grown leaves (RUML).<smiles>CCCCCCOC(=O)C(F)(F)C(F)(F)C(F)(F)F</smiles>

3,3-Dimethylbutyric acid 2,2,3,3,4,4,4-heptafluorobutylester

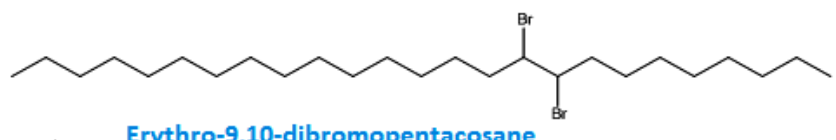

Erythro-9,10-dibromopentacosane

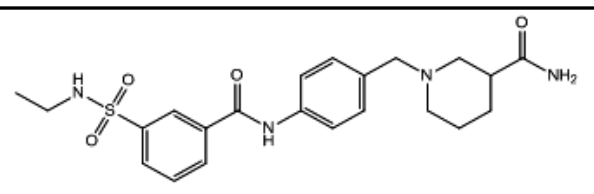

$\mathrm{N}$-[2-(4-Benzenesulfonyl-Piperazin-1-YL)-Ethyl]N'-(4-methyl-benzyl)-oxalamide

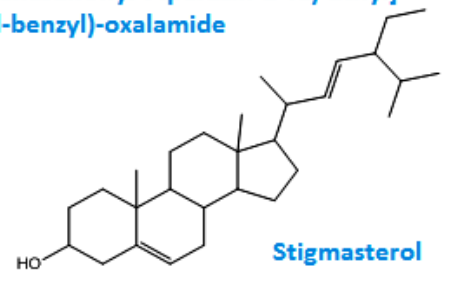<smiles>CCC(=O)OCC(C)CC</smiles>

1-Butanol, 2-methyl, propanoate

Figure 4B: Identified compounds in GC-MS profile of in vitro grown leaves (RUML). 
238

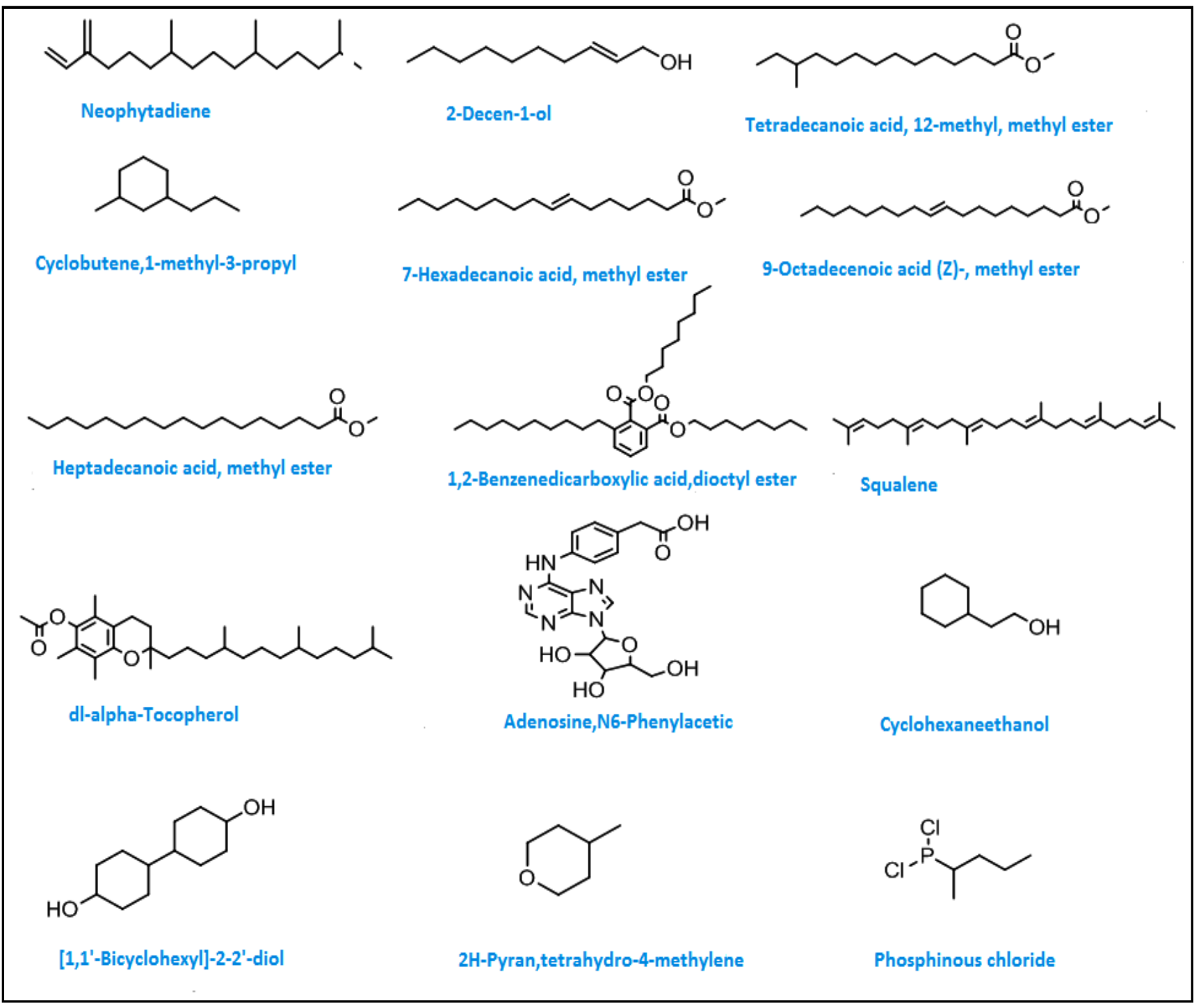

Figure 5A: Compounds identified in GC-MS profile of in vitro grown leaves (RUMR).<smiles>CC1=NCC(C)N1</smiles>

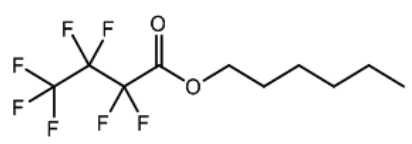

1H-Imidazole,4,5-dihydro-2,4-dimethyl

3,3-dimethylbutyric acid,2,2,3,3,4,4-heptafluorobutyl ester<smiles>CNS(=O)(=O)c1cccc(C(=O)Nc2ccc(CN3CCCC(C(N)=O)C3)cc2)c1</smiles>

N-[2-(4-Benzenesulfonyl-piperazin-1-yl)-ethyl]-n'-(4-methylbenzyl)-oxalamide

Figure 5B: Compounds identified inGC-MS profile of in vitro grown leaves (RUML). 


\section{Discussion}

Members of plant kingdom produce amazing diversity of low molecular weight organic compounds which have been classified into three prominent groups: primary (required directly for plant growth); secondary (mediate plant-environment interactions) and hormones (regulate physiological functions and metabolism) (Matthias and Kliebensteinb, 2020). Among these, secondary metabolites are unique and more of scientific interest as these help the plants to adapt and defend theirselves in various biotic and abiotic stressed environmental conditions (Ramakrishna and Ravishankar, 2011). Phytochemicals with ability to display therapeutical effects are fortuitous blessings for human health. However, biosynthesis and accumulation of these secondary metabolites are strongly influenced by various environmental factors, viz., temperature, humidity, light intensity, supply of water, minerals, and $\mathrm{CO}_{2}$, etc. This ability of biosynthesizing various types of secondary compounds and in different concentrations has been achieved by the plants in the course of evolution in order to shield theirselves from the selective notions of nature (Pichersky and Gang, 2000). Ladakh, also known as 'land of high passes' is an Indian state known for its rugged ecosystem and limited vegetative period of 4-5 months only (Kumar et al., 2013). However, a number of medicinal plant species (1100) have been found to grow on these steep and rocky mountains (Navchoo and Buth, 1989). Local medical practitioner combines these herbs with various other indigenous ingredients like mineral salts and animal products to develop traditional therapeutic formulations. These tremendous health promoting benefits of Himalayan medicinal plants has been traced to their unique bioactive secondary metabolites which in turn attributes the plants with tolerance to harsh climatic conditions of high altitude habitat (Kumar et al., 2017). R. cordifolia is one of perennial herbaceous medicinal plant species, found to grow actively in close proximity to water sources. In traditional medicinal system, different parts of this plant species are used for treatment of various ill conditions like skin diseases, diabetes, rheumatism, jaundice, stomach and urinary disorders (Gaurav et al., 2017). This plant species has been reported to contain different phytoconstituents like xanthopurpurin, manjishthin, nephthoquinones, pseudopurpurin, etc. (Devipriya and Siril, 2014). However, various regional and environmental restrictions, limit the commercial extraction of these phytoconstituents. Plant cell culture technologies have been effective tools for both studying and producing desired plant secondary metabolites under in vitro conditions along with improvement of plants for large scale production of secondary metabolites. Plant tissue culture is the science of growing plant cells, tissue or organs independently from mother plant on artificial nutrient media under controlled environmental conditions ( $\mathrm{Li}$ et al., 2017). In present study, an in vitro regeneration method for $R$. cordifolia has been developed using leaf and nodal explant collected from Leh region followed by GC-MS analysis to determine the phytochemical profile. Biosynthesis and accumulation of bioactive phytoconstituents are species specific and tissue specific which are further influenced by the environmental conditions, in which the source of explant is growing (Nielsen et al., 2019). Among the tested combinations of two cytokinins, i.e., BAP and $\mathrm{KN}$, maximum shoot induction and proliferation $(42.33 \pm 1.43)$ was observed in $1.0 \mu \mathrm{M}$ concentration of each of two cytokinin tested. A low concentration of BAP with high concentration of $\mathrm{KN}$ was found more effective for efficient shoots development. Further, numerous concentrations of three different hormones, viz., KN, BAP and NAA were investigated for multiple shoot regeneration from leaf explant. Equal concentration of BAP and KN without NAA was found more effective for shoot proliferation by indirect organogenesis. Synergistic effects of KN and BAP hormones were observed more efficient for multiple shoot induction whereas higher concentration of NAA in comparison to other two hormones was found to develop callus. Development of organs in in vitro culture depends on the concentration and balance of exogenously supplied phytohormones which either directly leads to organogenesis or induce the already present hormones with in cells for organ development (Mercier et al., 2003). Previously, $1.0 \mathrm{mg} / \mathrm{l} \mathrm{BAP}$ in combination with $0.02 \mathrm{mg} /$ 1 IAA was found optimum for effective shoot induction (5.2 shoots/ explant) (Radha et al., 2011). In another study carried out by Gurav et al. (2017), only bud sprouting was achieved in MS media supplemented with $3.0 \mathrm{mg} / \mathrm{l} \mathrm{BAP}$ and $0.1 \mathrm{mg} / \mathrm{l}$ IAA from nodal explant, whereas maximum number of shoots development (20$25)$ was observed in TDZ $(0.5 \mathrm{mg} / \mathrm{l})$ with $0.1 \%$ PVP containing MS media (Gaurav et al., 2017). Further, triumph of clonal propagation study depends on effective rooting of in vitro regenerated shoots (Faisal et al., 2006). It has been described that requirement of external supply of different concentrations of auxins for root induction depend upon inherent concentrations of auxins in plant tissue. In addition to this, plant genotype, age and type of explant, concentration and kind of auxin further influence the induction of roots (Li et al., 2017) Therefore, supplementation of correct concentration of specific auxin in culture medium is detrimental for adequate roots development (Mahendran and Bai, 2013). In pre sent study, IBA was found more effective for efficient root regeneration in comparison to NAA where a percent root regeneration of $99.67 \pm 0.33$ was achieved in $0.1 \mathrm{mg} / \mathrm{l} \mathrm{NAA}$. Similar efficiency of IBA for effective root regeneration has also been reported in $R$. cordifolia (Gaurav et al., 2017). Further, GC-MS analysis was carried out to determine the phytochemical profile of methanolic extract of both in vitro grown leaves (RUML) and roots (RUMR). Thirty nine chemical phytocompounds including 8 common bioactive constituents with various biological activities were identified in both extracts (Tables 1,2 ). These compounds have been found to show different biological activities, viz., antiinflammatory (octyl 2-methylpropanoate, 9-octadecenamide,), antimicrobial (neophytadiene; 1, 2-benzenedicarboxylic acid, dioctyl ester; gamma-sitosterol), antioxidant (heptadecanoic acid, methyl ester; 6-octadecenoic acid, methyl ester); pentadecanone; alphatocoferol), antidiabetic (stigmast-5-en-3-ol), antitumour (squalene), etc., along with other compounds were identified in both RUMR and RUML, suggesting the therapeutical potential of in vitro grown plants of $R$. cordifolia for various pharmaceutical applications. Previously, Gazi et al. (2015) identified rubiadin and purpurin in ethanolic extract of roots of $R$. cordifolia. To the best of our knowledge, this is the first report of establishment of in vitro culture of $R$. cordifolia through leaf explant. Further, for the first time, GC-MS analysis has been performed to determine the phytochemical profile of in vitro grown leaves and roots.

\section{Conclusion}

Present investigation has been focused on determination of phytochemical potential of in vitro grown plants of $R$. cordifolia grown in Leh-Ladakh. For the first time, this study has been carried out to establish an effective in vitro regeneration protocol using leaf explant which could be applied to aid in producing uniform 
propagules throughout the year for industrial purpose without destructing its natural habitat. A total of 20 compounds were identified in methanolic extract of in vitro grown leaves and 19 from roots depicting the profound potential of in vitro grown plants for pharmaceutical utility. Therefore, this work paves way for mass propagation and cultivation of this high value medicinal plant using biotechnological approaches. Also, a scope of in vitro synthesis of bioactive phytochemicals and their plausible elicitation using biotic and abiotic stresses is being suggested, further.

\section{Conflict of interest}

The authors declare that there are no conflicts of interest relevant to this article.

\section{References}

Adnan, M.; Chy, N.U.; Mostafa Kamal, A.T.M.; Azad, M.O.K.; Paul, A.; Uddin, S.B. and Cho, D.H. (2019). Investigation of the biological activities and characterization of bioactive constituents of Ophiorrhiza rugosa var. Prostrata (D. Don) and Mondal leaves through in vivo, in vitro, and in silico approaches. Molecules, 24(7):1367.

Ajoke, F.P.; Kaita, H. and Ilyas, M. (2014). Antibacterial activity of 1,2 benzenediccarboxylic acid, dioctyl ester isolated from the ethyl acetate soluble sub-portion of the unripe fruits of Nauclea latifolia. Int. J. Pure App. Biosci., 2:223-230.

Arunkumar, S. and Muthuselvam, M. (2009). Analysis of phytochemica constituents and antimicrobial activities of Aloe vera L. against clinical pathogens. World Journal of Agricultural Sciences, 5(5): 572-576.

Babu, A.; Anand, D. and Saravanan, P. (2017). Phytochemical analysis of Ficus arnottiana (Miq.) leaf extract using GC-MS analysis. IJPPR, 9(6):775-4.

Badyal, D.K.; Lata, H. and Dadhich, A.P. (2003). Animal models of hypertension and effect of drugs. Indian J. Pharmacol., 35(6): 349-362.

Belakhdar, G.; Benjouad, A. and Abdennebi, E.H. (2015). Determination of some bioactive chemical constituents from Thesium humile Vahl. J. Mater Environ. Sci., 6(10):2778-5.

Bhardwaj, A.; Shakil, N.A.; Jha, V. and Gupta, R.K. (2014). Screening of nutritional, phytochemical, antioxidant and antibacterial activity of underutilized seeds of Scirpus articulatus: The basis of Khubahi Ramdana industry. J. Pharmacogn. Phytochem., 3(4):311-320.

Bhardwaj, P.; Naryal, A.; Thakur, M.S.; Aggarwal, N.K.; Saxena, S.; Chaurasia, O.P. and Kumar, R. (2020) Comparative antioxidant, antibacterial, and GC-MS analysis of methanol extract's fractions and isolation of luteolin from leaves of trans-Himalayan Codonopsis clematidea. Ind. Crops Prod., 144:112046.

Bin-Nyeem, M.A.B. and Mannan, M.A. (2018). Rubia cordifoliaphytochemical and pharmacological evaluation of indigenous medicinal plant: A review. Int. J. Physiol. Nutri. Phys. Edu., 3(1): 766-771.

Cassano, R. (2012). Vitamin E chemistry, biological activity and benefits on the skin. In handbook of diet, nutrition and the skin, Wageningen Academic Publishers, pp:144-163.

Chandrasekaran, M.; Senthilkumar, A. and Venkatesalu, V. (2011). Antibacterial and antifungal efficacy of fatty acid methyl esters from leaves of Sesuvium portulacastrum L. Eur. Rev. Med. Pharmcol. Sci., 15:775-780.
Devi Priya, M. and Siril, E. A. (2014). Traditional and modern use of indian madder (Rubia cordifolia L.): An overview. Int. J. Pharm. Sci. Rev. Res., 25(1):154-164.

Devi P, M. and Siril, E. A. (2014). Traditional and modern use of indian madder (Rubia cordifolia L.): An overview. Int. J. Pharm. Sci. Rev. Res., 25(1):154-164.

Gaurav, A.M.; Sinha, R.; Mhase, A.G.; Rao, G.; Mangal, A.K and Srikanth, N. (2017). Conservation of Manjishtha - Rubia cordifolia L. through nodal culture. Journal of Drug Research in Ayurvedic Medicine, 2(4):267-273.

Gazi, S.; Sadath, A.; Luqman, S. and Rizwan, S.H. (2016). Gas chromatography mass spectrometry analysis of ethanolic extract of roots of Rubia cardifolia (MANJISTHA). Asian J. Pharm Clin. Res., 9(1):191-93.

Gharibi, S.; Sayed, B.E.; Saeidi, T.G.; Talebi, M. and Matkowski, A. (2019).The effect of drought stress on polyphenolic compounds and expression of flavonoid biosynthesis related genes in Achillea pachycephala Rech.f, Phytochem., 162:90-98.

Gnana, G.; Beulah, P.; Soris, P.T. and Mohan, V.R. (2018). GC-MS determination of bioactive compounds of Dendrophthoe falcata (L.F) Ettingsh: An epiphytic plant. IJHSR., 8:261-269.

Gurav, A.M.; Sinha, R.; Mhase, A.G.; Rao, G.; Mangal, A.K. and Srikanth N. (2017). Conservation of Manjishtha - Rubia cordifolia L. through nodal culture. J. Drug Res. Ayurvedic Sci., 2(4):263-273.

Huang, Z.R.; Lin, Y.K. and Fang, J.Y. (2009). Biological and pharmacological activities of squalene and related compounds: potential uses in cosmetic dermatology. Molecules, 14(1):540-554.

Hussein, H. M.; Hameed, I.H. and Ibraheem, O.A. (2016). Antimicrobial activity and spectral chemical analysis of methanolic leaves extract of Adiantum capillus-Veneris using GC-MS and FTIR spectroscopy. IJPPR, 8(3):369-416.

Islam, M.T.; Ali, E.S.; Uddin, S.J.; Shaw, S.; Islam, M.A. and Ahmed M.I. (2018), Phytol: A review of biomedical activities. Food Chem. Toxicol., 121:82-12.

Itokawa, H.; Qiao, Y.F. and Takeya, K. (1990). New arborane type triterpenoids from Rubia cordifolia var. pratensis and $R$. oncotricha. Chem. Pharm. Bull., 38(5):1435-1437.

Johnson, W.C. and William, O.W. (2002). Warfarin toxicity. J. Vasc. Surg., 35:413-421.

Kala, C.P. and Manjrekar, N. (1999). Ethnomedicobotany of Indian transHimalaya: A case study from Spiti. J. Econ. Taxon. Bot., 23:177183.

Kumar, J.; Dhar, P.; Tayade, A.B.; Gupta, D. and Chaurasia, O.P. (2013). Antioxidant capacities, phenolic profile and cytotoxic effects of saxicolous lichens from trans-Himalayan cold desert of Ladakh. PLoS One, 2:259-289.

Kumar, R.; Thakur, M.S.; Bhardwaj, P.; Bhardwaj, G.; Raghuvanshi, R. and Chaurasia, O.P. (2017). GC-MS profiling and bioactivity study of trans-Himalayan plant Centaurea depressa. Der. Pharma. Chem., 9:63-69.

Larranaga, M. D. and Lewis, R. J. (2016). Hawley's condensed chemical dictionary 14 th edition. John Wiley and Sons, Inc., New York, pp: 1002 .

Lewis, R. J. and Hawley, G.G. (2001). Hawley's condensed chemical dictionary 14 th edition. John Wiley and Sons, Inc., New York, pp:1124.

Li, S.; Huang, P.; Ding, G.; Zhou, L.; Tang, P.; Sun, M. and Lin, S. (2017). Optimization of hormone combinations for root growth and bud germination in Chinese fir (Cunninghamia lanceolata) clone leaf cuttings. Sci. Rep., 7(1):1-10. 
Mahendran, G. and Bai, V.N. (2014). Micropropagation, antioxidan properties and phytochemical assessment of Swertia corymbosa (Griseb.) Wight ex CB Clarke: A medicinal plant. Acta Physiol. Plan., 36(3):589-603.

Matthias, E. and Kliebensteinb, D.J. (2020). Plant secondary metabolites as defenses, regulators, and primary metabolites: the blurred functional trichotomy. Plant Physiol., 184:39-52.

Mercier, H.; Souza, B.M.; Kraus, J.E.; Hamasaki, R.M. and Sotta, B. (2003) Endogenous auxin and cytokinin contents associated with shoo formation in leaves of pineapple cultured in vitro. Braz. J. Plant Physiol., 15(2):107-112.

Morton, A.G. (1981). History of Botanical Science. An account of the development of botany from ancient times to the present day, Academic Press, London, pp:474.

Navchoo, I.A.; and Buth, G.M. (1989). Medicinal system of Ladakh, India. J. Ethnopharmacol., 26:137-146.

Nielsen, E.; Temporiti, M.E.E. and Cella, R. (2019). Improvement of phytochemical production by plant cells and organ culture and by genetic engineering. Plant Cell. Rep., 38(10):1199-1215.

Ogunmefun, O. T. (2018). Phytochemicals, God's Endowment of Curative Power in Plants. In phytochemicals-source of antioxidants and role in disease prevention. Intech. Open, pp:8-23.

Osuntokun, O.T. and Gamberini, M.C. (2019). Bioguided isolation, chemical purification, identification, antimicrobial and synergistic efficacy of extracted essential oils from stem bark extract of Spondias mombin (Linn). Int. J. Mol. Biol., 4(4):135-138.

Radha, R.K.; Shereena, S.R.; Divya, K.; Krishnan, P.N. and Seeni, S. (2011). In vitro propagation of Rubia cordifolia Linn., a medicinal plant of the Western Ghats. Int. J. Botany, 7(1):90-96.

Ramakrishna, A. and Ravishankar, G.A. (2011). Influence of abiotic stress signals on secondary metabolites in plants. Plant Signal Behav., 6(11):1720-1731.
Sharma, A.; Singh, T. and Vijayvergia, R. (2015). GC-MS analysis of bioactive phytocomponents from Rumex vesicarus. Int. Res. J. Pharm., 6(9):269-3.

Shekokar, A.V.; Borkar, K.M.; Pandao, P.O. and Londe, S.S. (2013). A Case Study of Manjistadi Taila with Kadalipatra and Bactigauze for local application in the Management of Burn. Int. J. Adv. Ayurveda, Yoga, Unani, Siddha and Homeopathy, 2:112-118.

Singh, R.; Dar, S.A. and Sharma, P. (2012). Antibacterial activity and toxicological evaluation of semi purified hexane extract of Urtica dioica leaves. J. Med. Plant Res., 6:123-135.

Son, J.K.; Jung, S.J.; Jung, J.H.; Fang, Z.; Lee, C.S.; Seo, C.S. and Woo, M.H. (2008). Anticancer constituents from the roots of Rubia cordifolia L. Chem. Pharm. Bull., 2:213-216.

Sujatha, S.; Anand, S.; Sangeetha, K.N.; Shilpa, K.; Lakshmi, J.; Balakrishnan, A. and Lakshmi, B.S. (2010). Biological evaluation of (3ß)-STIGMAST5-EN-3-OL as potent antidiabetic agent in regulating glucose transport using in vitro model. Int. J. Diabetes Mellit., 2(2):101109.

Surh, Y.J.(2003). Cancer chemoprevention with dietary phytochemicals. Nat. Rev. Cancer, 3(10):768-780

Tsay, H. S. and Agrawal, D. C. (2005). Tissue culture technology of Chinese medicinal plant resources in Taiwan and their sustainable utilization. Int. J. App. Sci. Eng., 3:215-223.

Venugopal, S. N. (2002). Simple formulations for primary health care uses based on ayurveda, foundation for revitalisation of local health traditions, Andra Pradesh Forest Department, pp:26-27.

Warrier, P.K.; Nambiar, V.P.K. and Ganapathy, P.M. (2001). Some important medicinal plants of the Western Ghats, India. A Profile, International Dev. Res. Cent., New Delhi, pp:329-342.

Yadav, R. N. S. and Agarwala, M. (2011). Phytochemical analysis of some medicinal plants. J. Phytol., 3(12):10-14. 